\title{
Çalışanlarda Erteleme Davranışının İş-Yaşam Dengesi Üzerine Etkisi: Konya İlinde Bir Araştırma
}

\author{
The Impact of Workers' Procrastination Behaviour on Work-Life Balance: A \\ Research in Konya Province
}

Halime KARA 1

\author{
Araştırma Makalesi / Research Article \\ Geliş Tarihi / Received: 26.01.2021 \\ Kabul Tarihi / Accepted: 23.05.2021 \\ Doi: 10.48146/odusobiad.868472
}

Atıf / Citation: Kara, H., (2021). "Çalıșanlarda Erteleme Davranışının İş-Yaşam Dengesi Üzerine Etkisi: Konya İlinde Bir Araştırma” ODÜSOBİAD 11(2), 467-482, doi: 10.48146/odusobiad.868472

\begin{abstract}
Öz
İnsanoğlu geçmișten günümüze içinde bulunduğu toplumda hayatını idame etmek için aktif bir rol üstlenmiștir. Bireyler çalışma hayatı içinde özel yaşamı ile iș hayatı arasında denge unsurunu oluşturma ve ikisini bir şekilde yürütme çabası içerisindedir. Fakat bu dengenin sağlanması o kadar kolay olmamaktadır. Bu dengeyi bozan birçok etmenin varlığı dengesizliğe neden olmaktadır. Bu etmenlerden birinin de insanların çağımızın hastalığı olarak kabul edilen erteleme davranıșına (prokrastinasyon) sahip olmaları veya bu davranışa eğilimli tutum sergilemeleridir. Bu davranıș insanoğlunun ișlerini farklı nedenlerle ertelemeye yönelmeleri ve geçici de olsa kendilerini rahat hissetmeleri olarak ifade edilebilir. Erteleme insanların günlük işlerinde, akademik hayatlarında ve hatta iş hayatlarında kendisini gösteren bir olgudur ve bu eylem kişilerin hayatlarını ciddi anlamda etkilemektedir. "Erteleme" ve "İș-Yașam dengesi" değișkenleri üzerine yapılan çalıșmalar farklı konularla ele alınmıştır. Yazında çoğunlukla erteleme üzerine yapılan çalışmalar akademik erteleme ile ilgilidir. Mevcut çalışmada ise akademik ertelemeden uzaklaşılarak Konya'da farklı alanlarda çalışan 148 kişinin oluşturduğu örneklem grubunun genel erteleme davranışlarının iş yaşam dengesine etkisinin olup olmadığı araştırılmıştır. Bu amaç doğrultusunda çalışanlarla online olarak anket çalışması yürütülmüştür. Örneklem grubundan elde edilen anketler SPSS 23 programı ile analiz edilmiştir. Hipotez testleri için regresyon analizi ve bağımsız örneklem t testi analizi yapılmıştır. Analizler sonucunda çalışanların genel erteleme davranışlarının iş yaşam dengeleri üzerine anlamlı bir etkiye sahip olduğu tespit edilmiştir. Bağımsız örneklem t testi sonucunda ise çalıșanlarda erteleme davranıșının medeni duruma göre farklılaștığı tespit edilmiștir. İș yașam dengesi çalışılan sektöre göre anlamlı farklılık göstermektedir. Dolayısıyla H1, H4 ve H6 hipotezleri kabul edilmiştir.
\end{abstract}

Anahtar Kelimeler Erteleme, Çalıșanlarda Erteleme Davranıșı, İș-Yașam Dengesi, Özel Sektör Çalıșanları, Kamu Çalışanları

\begin{abstract}
Humanbeings has taken an active role in maintaining their life in the society from past to present. Individuals are in an effort to create a balance between private life and business life and to carry out both in their working life. However, this balance is not so easy to achieve. The existence of many factors that disrupt this balance causes imbalance. One of these factors is that people have procrastination or tendency towards this behavior, which is accepted as the disease of our age. This behavior can be expressed as human beings tend to postpone their work for different reasons and feel comfortable, albeit temporarily. Procrastination is a phenomenon that manifests itself in people's daily work, academic life and even business life, and this action seriously affects people's live Studies on "procrastination" and "work-life balance" variables have been handled with different subject In the literature, studies on procrastination are mostly related to academic procrastination. In the present study, it was investigated whether the general procrastination behaviors of the sample group of 148 people working in different fields in Konya have an effect on the work-life balance by moving away from academic delay. For this purpose, an online survey was conducted with employee The questionnaires obtained from the sample group were analyzed with the SPSS 23 program. Regression analysis and independent sample t test analysis were performed for hypothesis test As a result of the analysis, the general procrastination behaviors of the employees have a significant effect on the work life balance. As a result of the independent sample t test, it was determined that procrastination behavior in
\end{abstract}

1 Yüksek Lisans Öğrencisi, Selçuk Üniversitesi, Konya, hlmkrcnuu@gmail.com:, ORCID ID:0000-0003-0561-6413 
employees differs according to marital statu On the other hand, work-life balance shows a significant difference according to the sector. Hence, H1, H4 and H6 hypotheses were accepted.

Keywords Procrastination, Procrastination Behavior of Workers, Work-Life Balance, Private Sector Employees, Public Sector Employees

\section{Giriş}

İnsanoğlunun küçük topluluklar halinde yaşadığı dönemde üyelerden birinin topluluğu alakadar eden herhangi bir şeyde erteleme davranışına yönelmesiyle "erteleme" kavramının ortaya çıktığı düşünülmektedir. Medeniyetler geliştikçe, kültür faaliyetlerine olan talepler artmış ve bu da beraberinde bireylerin erteleme davranışına olan fırsatlarını artırmıştır (Knaus, 2000, 153). Bu davranışın ortaya çıkışına dair açıklamalar akademisyenlerin farklı bakış açılarına göre birbirinden ayrılmaktadır. Farklar psikolojisi açısından bu davranıș diğer kișilik değișkenleri ile ilişkili bir özelliktir. Güdüsel veya motivasyonel psikoloji açısından bakıldığında bu davranıș diğer motivasyon veya öz düzenleme değişkenleri ile motivasyonel ve/veya istemli bir eksiklik olarak görülür. Klinik psikoloji açısından incelendiğinde ise erteleme anksiyete, depresyon ve stres ile ilişkili bir olgudur. Durumsal perspektifle bakıldığında ise bu davranış görev zorluğu gibi belirli durum özellikleri ile ortaya çıkmaktadır (Prem, Scheel, Weigelt, Hoffmann ve Korunka, 2018, 2). Zorluk, itiraz, belirsizlik ve son teslim tarihi baskısı, görevin ertelenmesini öngörmeye yardımcı olabilecek bir görevin özellikleri arasındadır (Harris ve Sutton, 1983, 988).

İnsanoğlu günlük veya işle alakalı olsun yapması gereken davranışları başka bir tarihe erteleme eğilimindedir. $\mathrm{Bu}$ erteleme, yapılması kesin olan görevleri son dakikaya bırakmaktır. Erteleme eylemi maliyetli olmasına rağmen kişi erteleme davranışı göstermektedir. İnsanların bu davranışının kabul edilebilirliği işlerin gecikmesiyle ortadan kalkmakta ve bir sorun haline gelmektedir (Aydemir, 2018, 1031). Erteleme bireylerin davranışlarını meşru kılmaya çalıştıkları bir alışkanlıktır. Araştırmalar neticesinde bu davranışın örgütler üzerinde olumsuz etkileri tespit edilmiştir (Beheshtifar, Hoseinifar ve Moghadam, 2011, 62). Yapılan araştırmalara göre bir çalışanın iş ortamında her gün internet kullanımı ve sosyalleşmeye kaybettiği iki saati vardır ve bu da sadece Amerika'da yılda ortalama 739 milyar dolar maaş kaybına neden olmaktadır (Hen, Goroshit ve Viengarten, 2021, 1). Ertelemenin maddi kayıplara neden olmasının yanı sıra kişinin psikolojisini de etkileyecek çıktıları mevcuttur. Beheshtifar vd. (2011) ertelemenin stresi beslediğini ve bunun işletme içerisinde oluşacak ertelemenin iş ile ilgili strese yol açacağını ifade etmektedirler. Çünkü bireyler erteleme ile kısa süreli rahatlamayı tercih ederken aynı zamanda verimsiz zaman yönetiminden kaynaklanan sıkıştırılmış bir program içerisinde kendini bulabilmektedir. Ya da zamanında başlamadığı görevin stresi ile acil olmayan ya da tolerans payı bulunan işlerde ertelemenin devam etmesine neden olabilmektedir. Dolayısıyla bireyler ertelemenin oluşturduğu stres sarmalı içerisinde düşük düzeyde verim ve memnuniyetle hayatlarına devam etmektedirler.

Çalışanın erteleme davranışı göstermesi örgütün verimliliği ve etkinliğine yönelik potensiyel olumsuz etkisine rağmen örgütsel davranış alanında çok az bir ilgi görmüștür (Weymann, 1988, 226). Son 10 yılda yapılan araştırmada işyeri ertelemesine olan ilgi daha da artmış ve çalışanların erteleme davranışları üzerine odaklanılmıştır. Geniş bir modern iş tabakası, zihinsel olarak sağlıklı insanlarda erteleme belirtilerinin varlığını doğrulamaktadır (Zabelina, Chestyunina, Trushina ve Vedeneyeva, 2018, 88).

Geçmișten günümüze büyük gelişim gösteren teknoloji, bilgiye olan ihtiyacın artması, şirketlerin müşterilerine daha hızlı dönüş yapabilmesi, değișimlere adapte olabilme, iş hayatının devamlı planlı hale gelmesi çalışanın baskı hissetmesine neden olan faktörlerden bir kaçı olarak ifade edilebilir. Çalışanların yoğun çalışma hayatları, işin çalışandan beklentileri iş yaşam dengesizliğinin oluşmasına neden olmaktadır (Apaydın, 2011, 48). İş-yaşam dengesi, çalışanların zaman ve enerjilerini iş ile hayatlarının diğer önemli yönleri arasındaki ayrımı destekleyen bir kavramdır. İş yaşam dengesi, işyerinin taleplerine ek olarak aile, arkadaş, toplum katılımı, maneviyat, kişisel gelişim, kişisel bakım ve diğer kişisel faaliyetlere zaman yaratmak için günlük bir çabadır (Vyas, Sajjan ve Hanji, 2015, 366).

İş ve yaşam dengesini ölçmek, çeşitli nesnel ve öznel boyutlara bakmayı ve insanların günlük yaşamlarında gerçekleştirmek istedikleri veya yapmak zorunda oldukları farklı etkinlikler arasındaki olası çatışma alanlarını tanımlamayı gerektirir (OECD, 2011, 124). İş yaşam dengesi üzerine yapılan araştırmalarda son yirmi yılda ekonomik belirsizlik, yeniden yapılanma ve iş 
rekabeti artışından kaynaklanan çalışmaların yoğun bir şekilde artmasına tanıklık eden ana tema olarak ortaya çıkmıștır (Sinha, 2013, 9).

Günümüz çalışanlarının iş, çocuklar, ev işleri, gönüllülük, eş ve yaşlı ebeveyn bakımı gibi birbiriyle yarışan birçok sorumluluğu vardır ve bu, bireyler, aileler ve yaşadıkları topluluklar üzerinde stres yaratmaktadır. İş ile hayat çatışması, işçileri, işverenlerini ve toplulukları etkileyen ciddi bir sorun haline gelmektedir (Dhas, 2015, 21660). Akhtar ve Malik yapmış oldukları araștırmada iş aile çatışmasını yaşayan çalışanların erteleme davranışları bu çatışmayı doğrudan ve anlamlı bir şekilde etkilediğini tespit etmişlerdir (Akhtar ve Faisal Malik, 2016). İș ve aile çatışması konusu iş ve yaşam dengesi konusunun temelini oluşturmaktadır. Aslında bir çalışanın iş piyasasına tam anlamıyla dahil olma isteği ile sevdiklerine en iyisini sunarken özünde mesleği ve kișisel sorumlulukları arasında sağlıklı bir denge kurma temelinde iş yaşam dengesi şekillenmektedir (Sharma ve Sharma, 2021, 1984).

Yazın ile ilgili alan taraması yapıldığında bu konunun iki değişkeninin birçok araştırmaya konu olduğu görülmüştür. İki değişken üzerine de hem yurtiçinde hem de yurtdışında birçok araştırma yapılmıștır. Ertelemenin (Prokrastinasyon) konu olduğu araștırmalar genellikle erteleme davranışının alt başlıkları olan genel erteleme ve akademik erteleme üzerinedir. Bu araştırmada çalışanların erteleme eğiliminde olmalarının iş yaşam dengesi üzerinde etkisinin olup olmadığının tespit edilmesi amaçlanmıştır. Çalışan ertelemesi üzerine sınırlı sayıda çalışmanın bulunması ve iş ve yaşam arasındaki dengeyi sağlayacak olan çalışan bireylerde erteleme davranışı göstermelerinin iş yaşamları ile sosyal yaşamları arasında etkiye yol açıp açmadı̆̆ı düşüncesiyle bu çalışma oluşturulmuştur.

\section{Çalışanlarda Erteleme Davranışı}

Yüzyıllardır erteleme insan zihnini aşmış bir olgudur. Günümüzde hala araștırmacıların birçoğu için gizemini korumaktadır. Geçmişten günümüze erteleme davranışı incelendiğinde üstlenilen işlerin daha ileri bir tarihte yerine getirilmesi olumsuz görülmüștür. İnsanlar erteleme davranışının ciddiyeti konusunda bilgisiz olmaları dolayısıla toplum olarak ertelemeyi bir sorun olarak görmemişlerdir. Ancak Ainslie (2005) ve Critchfield ve Kollins'e göre (2001) erteleme birçok sorunun merkezinde yer almaktadır; öyle ki bu davranış bazı dinlerde günah ve kötü bir şey olarak görülmektedir (Zainab H. Bhutto, Falak Z. Mohsin ve Niazi, 2011, 03).

Erteleme finanstan sağlığa birçok alanda giderek artan ilgi ile karşılaşmaktadır. Ancak bu davranışın ne olduğu ve nasıl faaliyete geçirildiği ile ilgili tartışmalar vardır. Sinirbilim ve davranışsal ekonomi alanları erteleme davranışına daha kötü olmasına rağmen ertelemeyi gerçekleștirdiğimiz irrasyonel bir gecikme olarak bakmaktadır (Steel, 2010, 2). Bu davranış 'Prokrastinasyon' yarın yapmayı planladığımız bir eylemi ertelemeyi tercih etmemizdir. İnsanoğlu mantıklı ya da mantıksız sebeplerle erteleme davranışlarıyla sorunlardan kaçmaya çalıșmaktadır (Azimi, Ajalli ve Amari, 2017, 676). Boice'ye göre (1996) erteleme kişilerin zor, önemli işleri yapma düşüncesinden kaçınarak, kolay olan ve hemen bir karşıllğı olan görevlerde kısa süreli tercih edilen bir davranış olarak görülür (Wyk, 2006, 9). "Erteleme, eylemin gecikmesinin daha kötü olması durumunun beklenilmesine rağmen kişinin isteyerek planlı bir şekilde ertelemede bulunması olarak kendi kendini düzenleyen bir formdur." (Nguyen, Steel ve Ferrari, 2013, 388). Bütün erteleme davranışlarını olumsuz olarak düşünmemek gerekir. Örneğin, stratejik ertelemeler, stratejinin bir parçası olan hayati bilgilerin toplanması, sınıflandırılması ve özümsenmesini içerdiğinde avantajlarını kanıtlamış olur (Knaus, 2000, 155). Gereksiz, mantıksız ve hatta zararlı olan gecikme, ertelemeyi stratejik gecikmeden ayıran şeydir. Stratejik gecikme durumunda, gecikmenin potansiyel olumsuz sonuçlarının farkında olunabilir. Bununla birlikte, ertelemenin aksine, stratejik gecikmeyle birlikte, bu olumsuz sonuçların uzun vadede gecikmenin olumlu sonuçlarından daha ağır basacağından emin olunur (Klingsieck, 2013, 25).

Günümüzde erteleme davranışı ciddi bir sorundur. İnsanların yarısı hem günlük hayatta hem de akademik çevrelerde erteleme davranışının kendileri için makul bir sorun olduğunu kabul etmektedirler (Dewitte ve Lens, 2000, 121). Bir görevi isteyerek ileri bir tarihe erteleme konusunda hiç suçluluk duymayan birini aramak samanlıkta iğne aramakla eş değerdir. Çoğu insan hayatlarında en az birkaç kez oyalanmaktan veyahut ertelemekten şikayetçi oldukları konusunda ortak düşünceye sahiptirler (Abbasi ve Alghamdi, 2015, 59). Ellis ve Knaus'a göre erteleme birbiriyle örtüşen üç unsurdan kaynaklanmaktadır. Bunlar; kendi kendine olumsuz konuşma, düşük engellenme toleransı 
ve karşıtlıktır. Bazı araştırmacılara göre düşük motivasyon, kötü zaman yönetimi, bunalmışlık hissi gibi unsurlar ertelemeye neden olmaktadır (Joubert, 2015, 14).

Erteleme davranışı sergileyen bireyin gecikmenin daha kötü olacağını bilmesine rağmen amaçlanan bir eylemin isteyerek ertelenmesi araştırmacılar tarafından bu davranışın tanımlanma şeklidir (Sirois ve Pychyl, 2013, 115). Araştırmacılar bireylerin erteledikleri altı yaşam alanını belirlemişlerdir: akademik ve iş, günlük rutinler ve yükümlülükler, sağlık, boş zaman, aile ve ortaklık ve sosyal ilişkilerdir (Hooda ve Devi, 2017, 108). Ertelemeye başvuran bireyler erteleme davranışı göstermeyenlere göre işleri daha yavaş ve daha fazla hata yaparak gerçekleştirirler (PearlmanAvnion ve Zibenberg, 2018, 265). Erteleme kavram olarak olumsuz bir çağrışıma sahiptir ve bu davranışı sergileyen insanlar kötü, zararlı ve aptal olarak görülebilirler. Kendini erteleme davranışını gösteren birisi olarak tanımlayan bireyler üstlendikleri görevleri zamanında bitirmek için gerçekçi hedefler belirleyerek bu davranıșı azaltmıș olacaklardır (Gupta, Hershey ve Gaur, 2012, 196).

İş hayatında işi erteleme hem bireyin hem de örgütün verimliliğini etkilemektedir. Örgütler için verimlilik çok önemli olduğu için, iş hayatında işi ertelemeye neden olabilecek unsurların belirlenmesi önemlidir. İşi geciktirmenin verimlilik yanında, bireyin performansı ve örgütsel stresle de ilişkisi vardır (Aksoy, 2017, 14). İş hayatında iş görenler birçok farklı nedenden dolayı önceliklerini değiștirebilmektedirler. Böyle bir değișikliğe giden veya erteleme eğilimi gösteren iş gören erteleme davranışını gerçekleştirmektedir (Aydemir, 2018, 1032). Birçok kişi, son anda çalışmaya başladıklarında bile, işlerini zamanında yetiştirdiklerini ve hatta zaman baskısı altında daha verimli ve yaratıcı fikirler üretebileceklerini söylemektedirler. Erteleme ile ilgili böyle bir düşünce dizini, birden fazla bir erteleme eğilimi olabileceğini ve hatta olumlu sonuçlar doğurabileceğini göstermektedir (Chu ve Choi, 2005, 246).

Son yllarda, iş yerindeki özellikle sorunlu ertelemeye artan bir ilgi olmuştur. İş yerinde artan sorumluluk ve özdenetim, piyasaya ürün sağlama ve teslim tarihlerine uyma gibi baskılar bireylere yapılacak çok şey olduğunu ancak yeterli zaman olmadığı hissini yaratır (Pearlman-Avnion ve Zibenberg, 2018, 264 - 265). İș alanı açısından, erteleme davranışları yapılan işin kalitesini bozmakta ve düşük performansa yol açmaktadır. Bu nedenle, erteleme, zaman kaybına, düşük performansa ve artan strese yol açan bireylerin kendilerini engelledikleri davranış olarak kabul edilmiştir (Kanten ve Kanten, 2016, 333).

\section{İş Yaşam Dengesi}

Hızlı bir yaşam temposuyla karşı karşıya kalan modern bir toplumda, iş ve kişisel yaşam arasındaki etkileşim, son birkaç yılda önemli bir araştırma konusu haline gelmiş̧ir (Koekemoer ve Mostert, 2010, 1). İş yaşam dengesi üzerine birçok tanım yapılmıştır ve Sirgy ve Lee (2018) bu tanımları iki kategoride ele almıștır: (1) iş ve iş dışındaki bireyin sahip olduğu çoklu rolleri içerisinde rol bağllığı ve (2) iş ve iş dışındaki rollerde azami çatışmadır. İş ve yaşam dengesi ile ilgili yapılan çalışmalar literatürde iş ve aile dengesi ve iş ve aile çatışması başlıkları ile araştırma konusu olmuştur. İş ve aile dengesi, minimum rol çatışması ile bireylerin evde ve iște iyi bir işleyişe ve memnuniyete sahip olmaları olarak ifade edilmektedir. Roller arasında yaşanan çatışma neticesinde iş ve aile çatışması ortaya çıkmaktadır (Hämmig ve Bauer, 2009, 88).

İş yaşam dengesi hem ülke hem de dünya genelinde önem kazanan bir kavramdır. İş yaşam dengesi kavramı, iş ve yaşam arasındaki zaman ve emeğin düzenlenmesine ilişkin politika tartışmalarında kullanılmıştır (Gümüş ve Türkyılmaz, , 67). İş ve yaşam arasındaki denge kavramında denge eşitliği ifade etmektedir. Bir başka ifadeyle iş ve yaşam arasındaki talepte eşitliğin sağlanmasıdır. Bu kavram özünde iş hayatındaki başarının sosyal yaşamdaki eğlence ile garanti edilmesidir(Pekdemir ve Koçoğlu Sazkaya, 2014, 315). Yapılan başka bir araştırmaya göre iş yaşam dengesi çalışanların bakış açısından 'kişisel/ailevi yükümlülükleri ile işin gereklerini yönetme çıkmazı' olarak tanımlanmaktadır. İşverenler açısından kavram 'çalışanların işteyken işlerine odaklanabilecekleri destekleyici bir şirket kültürü yaratmanın zorluğu’ olarak ifade edilmektedir (Lockwood, 2003, 3).

İnsanların iş dışındaki yaşamları ile iş yaşamları arasındaki ilişkiler veya birbiri üzerine olan etkilerine iliş̧kin araştırmalar oldukça eskilere dayanmaktadır. Bireyler iş dışında çevresindekilerle sürekli bir ilişki içindedir. Bu ilişskilerde önemli olan bireyin ailesi ile olan ilişkisidir (Özdevecioglu ve Doruk, 2009, 70). Aileleri ile işleri arasında dengenin pozitif veya negatif bir şekilde kurulabilmesi üç bileşenin eşitliği ile mümkün olabilmektedir. Bu değişkenler zaman dengesi, katılım dengesi ve 
memnuniyet dengesidir. Zaman dengesi, bireylerin işteki rolleri ve aile içindeki rolleri arasında tahsis edilen zamanın eşitliğini ifade etmektedir. Katılım dengesi, iş ve aile rollerinde eşit düzeyde psikolojik katılımı ve memnuniyet dengesi ise iş ve aile rollerinden eşit düzeyde memnuniyeti ifade etmektedir (Greenhaus, Collins ve Shaw, 2003, 513).

İş yaşam dengesi bir taraftan kariyer ve hırs gibi 'İş̧ ile öte yandan sağlık, keyif, boş zaman, aile veya manevi gelişim gibi 'Yaşam' arasında uygun önceliği içeren bir kavramdır. İş-yaşam dengesi, çeşitli iş ve kişisel etkinliklerin her biri için eșit sayıda zaman çizelgesi için bir denge olușturmak anlamına gelmektedir (Vyas vd., 2015, 366). Sturges ve Guest iş yaşam dengesini, ,iş yerinde ve evde en az rol çatışmasıyla memnuniyet ve iş/yaşam arasındaki iyi bir işleyiş olarak tanımlamaktadırlar (Sturges ve Guest, 2004, 6). Diğer bir ifadeyle "İş yaşam dengesi iş ve iş dışındaki istekler arasındaki çatışmanın kabul edilemez düzeylerde olmaması şeklinde tanımlanmaktadır. En yalın haliyle, iş yaşam dengesi; bireylerin işleri ile sosyal yaşamlarının etkin bir şekilde yönetilmesidir." şeklinde ifade edilebilmektedir (Akın, Ulukök ve Arar, 2017, 114).

Maad'a göre (2008) "Yaşamak için çalışıyoruz, çalışmak için yaşamıyoruz" ifadesi hayat ile iş arasında önceliklerini dengelemeye çalışan iş görenler için önemlidir (Gulbahar, Ch, Kundi, Qureshi ve Akhtar, 2014 , 2). Birçok çalışanın karşılaştığı zorluk, iş ile hayat arasında dengeyi bulmaktır. Bir kişinin ne kadar başarıll, zengin veya fakir olabileceği dikkate alınmaksızın, herkes iş, aile ve diğer faaliyetlere tahsis etmek için her gün aynı zamana sahiptir. İş yaşam dengesi terimi, işlerinde yeterli zaman harcayan ve aynı zamanda aile, hobiler ve toplum katılımı gibi diğer uğraşlar için yeterli zaman harcayan insanlara atıfta bulunmaktadır (Smith, 2010, 1).

Diğer taraftan iş yaşam dengesini ölçmek zordur. Nedenlerinden birincisi, bireylerin 'çok fazla' ve 'çok az' arasındaki keskin çizgisinin, bireylerin tercihlerine, önceliklerine ve hane halkı koşullarına göre farkllık göstermesidir. Örneğin aynı saatlerde çalışan iki kişi, işlerinden ne kadar keyif aldıklarına ya da büyütecekleri çocuk olup olmamasına göre çok farklı refah seviyeleri yaşayabilirler ve benzer şekilde, bu iki kişinin, zaman ayırmayı seçmekte özgür olup olmadıklarını veya bunun yerine bunu yapmaya zorlandıklarını da belirtmektedir. Íkincisi, çeşitli etkinliklere ve zamana karșı objektif ayrımın yanı sıra, belirleyici etkenlerine göre kişilerin "zaman çıkmazını" deneyimleyip deneyimlemediğine bakmak önemlidir; yani gün içinde her şey için yeterli zamanın olmaması stresli bir durumdur (OECD, 2011, 124).

İş yaşam dengesi iş görenin hayatında ve davranışlarında önemli sonuçlara neden olmaktadır. Çalışma saatlerinin düzensizliği, vardiyalı çalışma sistemi, rol belirsizliği, rol çatışması, iş güvenliğinin olmayışı, aşırı ya da az iş yükü, ücretin yetersiz olması, çalışma ortamından kaynaklanan fiziksel etmenler gibi çok sayıda faktör çalışanlar üzerinde olumsuz etkiye yol açmakta ve çalışanların sağlı̆̆ını tehdit etmektedir (Korkmaz ve Erdoğan, 2014, 541). Bu tip faktörler kişilerin iş yaşam dengesizliğine etki etmekte ve beraberinde iş kazaları, çalışanların tatminsizliği ve ailevi problemler gibi unsurları doğurmaktadır.

Değişen teknoloji ile birlikte iş hayatında önemli değişimler ortaya çlkmış ve bu değişimler beraberinde işletmeler arasındaki rekabet ortamının artışına neden olmuştur. Ortaya çıkan değişimler ile birlikte bireylerin iş ve hayatları arasındaki dengenin sağlanması da yazında önemli bir konu olarak yer almaya başlamıştır (Durna ve Babayiğit, 2015, 727). Araştırmalar iş ve evin (ya da ailenin) çalışan bireyler arasında önemli iki unsur olduğunu vurgulamaktadır. Bazıları sadece iş aracılığıyla kendimizi gerçekleştirdiğimizi iddia edebilir fakat gerçekten kapsayıcı bir kendini gerçekleștirme süreci hem iş hem de yaşamımızı bütünleștirmektedir (Igbinomwanhia, Iyayi ve Iyayi, 2012, 110). Bu nedenle birey çalıştığı kurumda iş için hayatından ya da hayatı için işinden vazgeçmemelidir. Yani kişi bir tarafa yönelirken diğer tarafı aksatma eğilimi içinde olmamalıdır. İkisi arasında dengeyi sağlamalıdır. Sağlanmaması durumunda bunun iş görenlerin hayatında strese yol açabileceği düşünülmektedir ve bu da iş görenlerin strese dayalı çatışma yaşamalarına neden olan unsurlardan biri olarak karşımıza çıkabilmektedir. Strese dayalı çatışma, bireyin işyerindeki veya aile içindeki rollerinden birinin birey üzerinde stres yaratması ve bu stres bireyin diğer rollerini etkilemesi durumunda ortaya çıkar ve bu iş ve yaşam arasında dengesizliğin olduğu duruma ortaya çlkar (Delecta, 2011, 187). 


\section{Çalışanlarda Erteleme Davranışı ve İş Yaşam Dengesi}

Erteleme üzerine araştırmalar geçtiğimiz 30 yıl içerisinde daha popüler hale gelmiştir (Metin, Peeters ve Taris, 2018, 228). Bu konu üzerine araştırma ve teori artmaya devam ederken, ertelemenin potansiyel ciddiyetinin olması gerektiği kadar geniş çapta kabul edilmemesi bu alandaki araştırmacılar arasında ortak bir endişe oluşturmaktadır (Pychyl ve Flett, 2012, 203).

Erteleme araştırmaları çoğu kez öğrencilerin oluşturduğu örneklem gruplarını kullanmıştır. Araştırma grubunu öğrencilerin oluşturmadığı araştırmalar 'iş yerinde erteleme', 'iş arayanlar arasında erteleme', 'mahalle sakinleri arasındaki yetişkinlerde sağlıkla ilgili erteleme', 'alışverișe ilişkin erteleme' geçmişten günümüze erteleme araştırmaları sağlık, iş, ilişkiler ve akademideki ertelemeleri incelemiştir (Klingsieck, 2013, 30).

İşyerinde ertelemeye ilişkin çok az araştırma yapılmıştır (van Eerde, 2016, 233). İş yerinde erteleme, amaçlanan bir işi yerine getirmede bir tür öz denetim başarısızlığıdır (Metin, Taris ve Peeters, 2016). Literatürde çalışan bireylerde erteleme davranışı üzerine çalışmalar kısıtlıdır. Bu çalışmalar örgütlerde görevin ertelenmesi (Harris ve Sutton, 1983), ertelemenin iş yerindeki etkisi ve iş yerinin erteleme üzerindeki etkisi (Nguyen vd., 2013), erteleme ve iş yerindeki refah (van Eerde, 2016), iş yerinde erteleme (Ferrari, 1992), mavi ve beyaz yakalı çalışanlar arasında erteleme (Hammer ve Ferrari, 2002), iş yerindeki ertelemenin ölçülmesi (Metin vd., 2016), günlük çalışma hayatında erteleme (Prem vd., 2018) çalışan ertelemesi üzerine yapılan çalışmalara örnektir.

İș yaşam dengesi; bireylerin ișleri ile sosyal yaşamlarının etkin bir şekilde yönetilmesidir (Akın vd., 2017, 114). İş yaşam dengesi çalışanın kendisini iyi hissetmesi için zekice tasarlanmış bir insan kaynağı yönetim aracıdır (Altıok Gürel, 2018, 32). İş yaşamı ve sosyal yaşamın bütünleşmesi yetișkinlik döneminin başlangıç ve ortalarının kritik bir görevidir (Jayanthi ve Vanniarajan, 2012, 24). İş ve yaşam arasındaki denge iş ve aile rollerindeki eşit deneyimleri yansıtmakta (Aziz, Adkins, Walker ve Wuensch, 2010, 74) ve iş ve yaşam arasında dengenin edinilmesi işyerinde üretkenliği artırdığı ve dolayısıyla örgütsel performansı etkilediği için çalışanlar ve kurumlar için önemli olmaktadır (Bobat, Mshololo ve Reuben, 2012, 227). Bireysel düzeyde iş yaşam dengesi, bireylerin yaşamlarının diğer boyutlarıyla (ev, aile, sağlık, sosyal aktivite, özel ilgi alanları vb.) işe katılma becerilerini ifade etmektedir. Bu açıdan bakıldığında, iş yaşam dengesi, bir bireyin yaşamındaki psikolojik refah, yüksek benlik saygısı, memnuniyet ve genel uyum duygusu sağlar (RichertKaźmierska ve Stankiewicz, 2016, 680). Bireylerin iș ve yaşamları arasında dengeyi oluștururken çalışma hayatları sonrasında bireysel memnuniyetin sağlanması amacıyla iş dışında da farklı faaliyetlerle ilgilenmek isteyeceklerdir ve bu da ancak iş ve yaşam arasında dengenin sağlanmasıyla mümkün olmaktadır (Topaloğlu, Sönmez ve Yazgan, 2019, 62).

İş yerinde erteleme eğiliminde olan bireyler uzun vadeli hedefleri yerine getirme pahasına tüm enerjilerini kısa vadeli olanlara yöneltebilirler. İdeal olan ise bireylerin kişisel enerjilerini kurumsal kaynakları en üst düzeye çıkartacak üretkenliği arttırmak ve verimsizliği azaltmak gibi temellerle denge unsurunu oluşturma çalışmalıdırlar. Maalesef erteleyiciler kendilerine zamanı değerlendirecek kısa bir süre bırakmaktadırlar ve bu da ideal olanın altında bir performansa yol açmaktadır (Gupta vd., 2012, 196). Dolayısıyla bireylerin hem iş hem de özel hayatlarında ertelemeden kaçınmaları gerektiği düşünülmektedir. Dengenin ortadan kalması sadece özel hayatta değil aynı zamanda iş hayatında da bireyin zamanını doğru ayarlayamamasına ve akabinde oluşacak düşük performansla birlikte bireyin tatminsizliğine neden olacağı bir döngünün oluşmasına neden olacaktır.

İş ve yaşam arasında dengeyi oluşturma bireylerin hayatını önemli ölçüde etkilemektir. Yapılan araştırmalar sonucunda ulusal ve uluslararası yazında iş yaşam dengesi üzerine yapılan araştırmalar incelendiğinde bireylerin erteleme davranışlarının iş yaşam dengesi üzerine etkisinin olup olmadığına dair bir çalışmaya rastlanılmamıştır. İş yaşam dengesini kurabilmek iyi organize edilmiş bir yaşam şemasını ve sağlıklı bir işleyişi gerektirir. İsteyerek belirli görevlerde/işlerde bireylerin ertelemeye yönelmesi günü kurtaran bir davranış olsa da bekletilen görevler/işler bitirme zamanı geldiğinde bireyin hayatındaki başka görevlerin/işlerin ertelenmesine ve bununda bireyin hayatında dengesizliğe neden olabilecek başka davranışları doğurabileceği düşünülmektedir. 


\section{Araştırmanın Amacı ve Modeli}

Araştırmanın amacı Konya'da özel ve kamu sektöründe çalışan bireylerin erteleme davranışlarının iş yaşam dengelerine etkisini incelemektir. Hayatın farklı alanlarında erteleme davranışının ele alınması tek bir bağlamda değil farklı bağlamlarda da bu davranışın etkisinin olduğu ve dikkate alınması gereken bir davranış eğilimi olduğu yapılan araștırmalarla ortaya konmuștur. Bireyin kendi iradesi sonucunda ortaya çıkan bu davranış iş ortamında da kendini göstermektedir. Çalışan bireylerin erteleme davranışlarının hem örgüte hem de kendilerine olumsuz etkilerinin olacağı düşünülmektedir. Bireylerin genel erteleme eğilimlerinin çıktısı olarak iş yaşam dengesinde etkinin gözlemlenmesi açısında yapılan çalışma önemli olmaktadır. Bu amaç doğrultusunda aşağıdaki hipotezler geliştirilmiştir.

H1: Çalışanların erteleme davranışlarının iş yaşam dengesi üzerine etkisi vardır.

H2: Erteleme davranışı ve cinsiyet değişkeni arasında anlamlı farklılıklar vardır.

H3: Erteleme davranışı ve çalışılan sektör değişkenini arasında anlamlı farklılıklar vardır.

H4: Erteleme davranışı ve medeni durum değişkeni arasında anlamlı farklılıklar vardır.

H5: İş yaşam dengesi ve cinsiyet değişkeni arasında anlamlı farklılıklar vardır.

H6: İş yaşam dengesi ve çalışılan sektör değişkeni arasında anlamlı farklılıklar vardır.

H7: İş yaşam dengesi ve medeni durum değişkeni arasında anlamlı farklılıklar vardır.

\section{Araştırma Yöntemi}

Çalışma ampirik bir araștırma niteliğindedir ve veri toplama aracı olarak anket tekniğinden faydalanılmıştır. Hazırlanılan anket 3 bölümden oluşmaktadır. Birinci bölümde katılımcılara ilişsin demografik bilgileri edinebileceğimiz ifadeler vardır. İkinci bölümde çalışanların genel erteleme düzeylerine ilişkin ifadeler bulunmaktadır. Üçüncü bölümde ise iş yaşam dengesine ilişsin ifadeler yer almaktadır. Genel Erteleme Ölçeği Çakıcı'nın (Ç. D. Çakıcı, 2003) çalışmasından alınmıştır. İş Yaşam Dengesi Ölçeği ise çalışmasından alınmıştır. Kullanılan her iki ölçek de 5'li Likert tipindedir. Veri analizinde ölçeklerin iç tutarlılık değerini bulmak için Cronbach's Alpha değerine bakılmıştır. Genel Erteleme Ölçeğinin iç tutarlılık değeri \%87,2, İş-Yaşam Dengesi Ölçeğinin de iç tutarlılık değerinin \%88,6 olduğu belirlenmiştir.

$\mathrm{Bu}$ araştırmanın evrenini Konya ilinde bulunan özel ve kamu çalışanları oluşturmaktadır. Araştırma örneklemini basit tesadüfi yöntemle belirlenen 158 çalışan oluşturmaktadır. Katılımcılardan alınan anketlerden 10 tanesi incelemeye uygun bulunmadığı için analizlerden çıkartılmıștır. Salgın dolayısıyla yüz yüze anket yapılamamıştır. Anketler online olarak katılımcılara iletilmiştir ve anket uygulaması 2020 yllının Eylül ve Ekim aylarında gerçekleșmiștir. Analize katılan örneklem büyüklüğü değişken başına 5 'ten fazla geçerli ankete ulaşılmış olması nedeniyle evreni temsil etmede yeterli olduğu şeklinde değerlendirilmiștir (aktaran Çetinkaya ve Güleç, 2018, 280).

\section{Veri Analizi ve Bulgular}

\section{Demografik Bulgular}

Ankete katılım sağlayan bireylerin demografik özellikleri Görsel 1'de görülmektedir. Tanımlayıcı istatistiklere bakıldığında cinsiyet açısından katılımcılar arasında yarı yarıya bir katılım söz konusudur. Katılımclların büyük bir çoğunluğunun yaș aralığının 25 - 30 olduğu görülmekte ve sektörde çalışma süresi 1 ila 5 yıl arasında değişmektedir. Katılımcıların büyük bir çoğunluğu özel sektör çalışanlarından oluşmaktadır. 


\begin{tabular}{|c|c|c|c|}
\hline \multicolumn{2}{|c|}{ Demografik Bulgular } & $f$ & Oran (\%) \\
\hline \multirow{3}{*}{ Cinsiyet } & Kadın & 74 & 50 \\
\hline & Erkek & 73 & 49,3 \\
\hline & Cevapsız & 1 & 0,7 \\
\hline \multirow{4}{*}{ Yaş } & $25-30$ yaş & 92 & 62,2 \\
\hline & 31 - 36 yaş & 19 & 12,8 \\
\hline & $37-42$ yaş & 18 & 12,2 \\
\hline & 43 ve üstü & 19 & 12,8 \\
\hline \multirow{2}{*}{ Medeni Durum } & Evli & 69 & 46,6 \\
\hline & Bekar & 79 & 53,4 \\
\hline \multirow{3}{*}{ Eğitim Durumu } & Lise ve altı & 24 & 16,2 \\
\hline & Lisans & 98 & 66,2 \\
\hline & Lisansüstü & 26 & 17,6 \\
\hline \multirow{5}{*}{ Çalışma Hayatında Geçirilen Süre } & $1-5$ yll & 85 & 57,4 \\
\hline & $6-10$ yll & 27 & 18,2 \\
\hline & $11-15 \mathrm{yll}$ & 10 & 6,8 \\
\hline & $16-20 \mathrm{yll}$ & 10 & 6,8 \\
\hline & 21 ve üstü & 16 & 10,8 \\
\hline \multirow{2}{*}{ Çalışılan Sektör } & Özel & 104 & 70,3 \\
\hline & Kamu & 44 & 29,7 \\
\hline
\end{tabular}

Görsel 1: Katılımcıların Demografik Özellikleri

\section{Genel Erteleme Ölçeği Faktör Analizi}

Çakıcı'nın (2003) araştırmasından alınan genel erteleme ölçeği örneklem açısından farklılık gösterdiği için faktör analizi uygulanmıştır (Görsel 2). Açıklayıcı faktör analizinde, KMO değeri 0,801 bulunmuştur. Bu değerin 0,80'nin altında olmaması iyi bir seviyede olduğunu ve ifadeler arasında bağlantı olduğuna işarettir. 


\begin{tabular}{|c|c|c|c|}
\hline \multirow{6}{*}{ 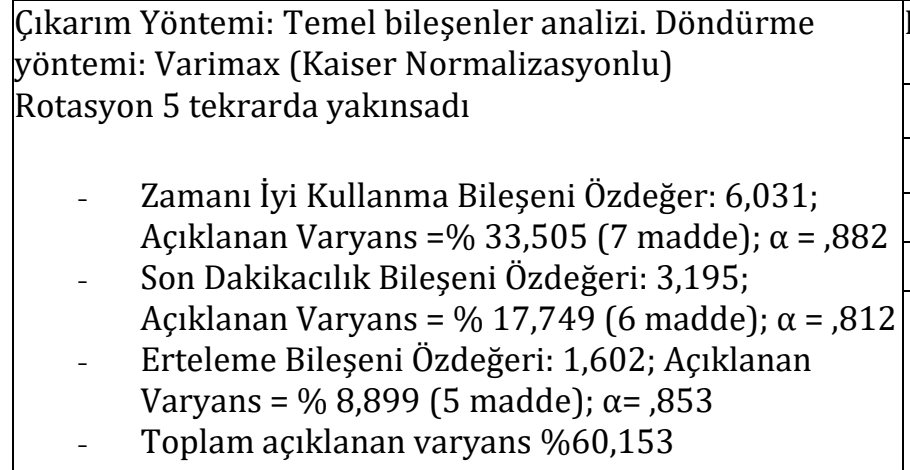 } & \multirow{2}{*}{\multicolumn{3}{|c|}{$\begin{array}{c}\text { Kaiser-Meyer-Olkin örneklem yeterliliği } \\
=, 801\end{array}$}} \\
\hline & & & \\
\hline & \multicolumn{3}{|c|}{ Df $($ Serbestlik derecesi) $=153$} \\
\hline & \multicolumn{3}{|c|}{ Sig. $=, 000$} \\
\hline & \multicolumn{3}{|c|}{ Bileşenler } \\
\hline & $\begin{array}{l}\text { Zamanı İyi } \\
\text { Kullanma }\end{array}$ & $\begin{array}{c}\text { Son } \\
\text { Dakikacılık }\end{array}$ & Erteleme \\
\hline İşlerin bitirilmesi için zamanımı iyi kullanırım & 0,851 & & \\
\hline İşlerimi gereken zamandan daha kısa sürede bitiririm & 0,822 & & \\
\hline İşleri zamanında bitiririm & 0,794 & & \\
\hline İşleri bitirdiğimde kontrol etmek için zamanım kalır & 0,78 & & \\
\hline İşleri ertesi güne bırakmak tarzım değildir & 0,764 & & \\
\hline Önemli işleri bana verilen zamandan daha önce bitiririm & 0,71 & & \\
\hline $\begin{array}{l}\text { En sıkıcı işlerin yapılabilmesi için bile mutlaka zamanında } \\
\text { başlarım }\end{array}$ & 0,66 & & \\
\hline Ne yapar eder işlerimi son dakikaya bırakırım & & 0,744 & \\
\hline $\begin{array}{l}\text { Ailem ve arkadaşlarım benim işleri hep son dakikada } \\
\text { yaptığımı söylerler }\end{array}$ & & 0,731 & \\
\hline Yapmak zorunda olduğum işleri son dakikaya bırakırım & & 0,721 & \\
\hline $\begin{array}{l}\text { Bir konuda karar vermiş olsam bile, harekete geçmeyi son } \\
\text { dakikaya bırakırım }\end{array}$ & & 0,688 & \\
\hline Sıklıkla iki ayağım bir pabuca girer & & 0,648 & \\
\hline $\begin{array}{l}\text { Ailem ve arkadaşlarım randevularıma hep geç kaldığımı } \\
\text { söylerler }\end{array}$ & & 0,51 & \\
\hline $\begin{array}{l}\text { İslerimi zamanında yapmadığım için maddi manevi zarara } \\
\text { uğrarım }\end{array}$ & & & 0,802 \\
\hline $\begin{array}{l}\text { İşlerimi yapmak için gereken zamanı çoğu kez yanlış } \\
\text { hesaplarım }\end{array}$ & & & 0,785 \\
\hline İş işten geçtikten sonra harekete geçerim & & & 0,761 \\
\hline Çok gerekli bir şeyi bile genellikle son dakikada yaparım & & & 0,62 \\
\hline Önemli işlerimi yapmayı da son dakikaya bırakırım & & & 0,602 \\
\hline
\end{tabular}

Görsel 2: Faktör Analizi Çıktıları

\section{Doğrusal Regresyon Analizi}

Araştırma hipotezimizi test etmek için doğrusal regresyon analizi yapılmıștır. Görsel 3'te yer alan regresyon analizi sonuçlarına göre çalışanların erteleme davranışlarının iş yaşam dengesi üzerinde anlamlı bir etkiye sahip olduğu $\left(R^{2}=, 186 ; p=, 000\right)$ belirlenmiştir. 


\begin{tabular}{|c|c|c|c|c|c|c|c|c|}
\hline \multicolumn{7}{|c|}{ Bağımsız Değişken / Çalışanlarda Prokrastinasyon } \\
\hline $\begin{array}{c}\text { Bağımlı } \\
\text { Değișken/İş-Yaşam } \\
\text { Dengesi }\end{array}$ & Sabit sayı & Beta & $\begin{array}{c}\text { Adjusted R } \\
\text { Square }\end{array}$ & $\begin{array}{c}\text { R } \\
\text { Square }\end{array}$ & F & $\begin{array}{c}\text { Sig. } \\
\text { Level }\end{array}$ & Std. Hata & T değeri \\
\cline { 2 - 9 } & 4,485 & $-0,432$ & 0,181 & 0,186 & 33,534 &, 000 & 0,6519 & $-5,79$ \\
\hline
\end{tabular}

Görsel 3: Doğrusal Regresyon Analizi

\section{Bağımsız Örneklem T Testi Sonuçları}

H2, H3 ve H4 hipotezlerini test etmek için bağımsız örneklem $t$ testi analizi yapılmıştır. Bulgular Görsel 4'te yer almaktadır. Analiz sonucuna göre çalışanların erteleme davranışları cinsiyetlerine, çalıştıkları sektörlere bağlı olarak farklılık göstermemektedir. Ancak katılımcıların medeni durumuna göre çalışan bireylerin erteleme davranışları farklılık göstermektedir. Bekar çalışanların erteleme davranışına ilişkin görüşlerinin ortalaması (Ort.=2.11;SS=.62) evli çalışanların erteleme davranışına ilişkin görüşlerinin ortalamasından (Ort.=1.87;SS=.58) daha yüksek çıkmıştır. Buna göre bekar çalışanların evli çalışanlardan daha fazla erteleme davranışı gösterdikleri sonuca çıkarılır.

\begin{tabular}{|c|c|c|c|c|c|c|}
\hline Cinsiyet & $\mathbf{N}$ & Ort. & SS & SD & $t$ & $\mathbf{P}$ \\
\hline Kadın & 74 & 2.06 & .57 & \multirow{2}{*}{145} & \multirow{2}{*}{1.107} & \multirow{2}{*}{.270} \\
\hline Erkek & 73 & 1.95 & .64 & & & \\
\hline Çalışılan Sektör & $\mathbf{N}$ & Ort. & SS & SD & $\mathbf{t}$ & $\mathbf{P}$ \\
\hline Özel & 104 & 2.03 & .63 & \multirow{2}{*}{146} & \multirow{2}{*}{.840} & \multirow{2}{*}{.402} \\
\hline Kamu & 44 & 1.93 & .57 & & & \\
\hline Medeni Durum & $\mathbf{N}$ & Ort. & SS & SD & $\mathbf{t}$ & $\mathbf{P}$ \\
\hline Evli & 69 & 1.87 & .58 & \multirow{2}{*}{146} & \multirow{2}{*}{-2.380} & \multirow{2}{*}{.019} \\
\hline Bekar & 79 & 2.11 & .62 & & & \\
\hline
\end{tabular}

Görsel 4: Cinsiyet, Çalışılan Sektör ve Medeni Durumun Erteleme Ölçeğine Ait Sonuçları

H5, H6 ve H7 hipotezlerini test etmek için yapılan bağımsız örneklem t testi bulguları Görsel 5 'te yer almaktadır. Analiz sonucunda iş yaşam dengesinin cinsiyet ve medeni duruma göre farklılık göstermediği ancak çalışılan sektöre bağlı olarak farklılık gösterdiği $t(146)=-2.65 ; p=0.009$ ortaya çıkmıştır.

\begin{tabular}{|c|c|c|c|c|c|c|}
\hline Cinsiyet & $\mathbf{N}$ & Ort. & SS & SD & $t$ & $\mathbf{P}$ \\
\hline Kadın & 74 & 3.47 & .69 & \multirow{2}{*}{145} & \multirow{2}{*}{.137} & \multirow{2}{*}{.891} \\
\hline Erkek & 73 & 3.45 & .75 & & & \\
\hline Çalışılan Sektör & $\mathbf{N}$ & Ort. & SS & SD & $\mathbf{t}$ & $\mathbf{P}$ \\
\hline Özel & 104 & 3.36 & .71 & 146 & -2.65 & .009 \\
\hline
\end{tabular}




\begin{tabular}{|c|c|c|c|c|c|c|}
\hline Kamu & 44 & 3.70 & .68 & & & \\
\hline Medeni Durum & $\mathbf{N}$ & Ort. & SS & SD & t & P \\
\cline { 1 - 4 } Evli & 69 & 3.57 & .69 & \multirow{2}{*}{146} & 1.707 & .090 \\
\hline
\end{tabular}

Görsel 5: Cinsiyet, Çalıșılan Sektör ve Medeni Durumun İş Yaşam Dengesi Ölçeğine Ait Sonuçları

\section{Sonuç ve Öneriler}

Erteleme davranışı hayatın her alanında bireylerin deneyimlediği ve bir kesimin öz denetim eksikliği nedeniyle diğer bir kesimin ise stratejik amaçlı gerçekleştirdiği bir tür davranıştır. Böyle bir davranış artık hayatın bir parçası haline gelmiştir ve bir görevin yerine getirilmesi başka bir görevin ertelenmesine neden olabilmektedir. Erteleme artık çoğumuz için makul bir davranış haline dönüșmüștür. Kısa süreli rahatlamamıza, günü kurtarmamıza yol açsa da aslında bu davranıș sağlığı, iş verimini, üretkenliği dolayısıyla bireyin düzenini ve çevresini etkileyen bir davranıştır. $\mathrm{Bu}$ davranışın çalışan kesim tarafından kabul edilmesi hayatlarında dengesizliğe yol açabilir. Konya ilinde yaşayan çalıșan bireylerin erteleme eğilimlerinin iş yaşam dengesi üzerine etkisini tespit etmek amacıyla mevcut araştırma yapılmıştır.

Yapılan çalışma sonucunda çalışanların genel erteleme davranışlarının iş yaşam dengeleri üzerine anlamlı bir etkisinin olduğu sonucuna ulaşılmıştır. Akhtar ve Faisal Malik yapmış oldukları çalışmada iș ve aile çatıșmasının erteleme davranıșı üzerinde anlamlı bir etkiye sahip olduğunu tespit etmişlerdir (Akhtar ve Faisal Malik, 2016). Bu araştırma sonucuna göre bireylerin aileyle bağlantılı görevlerini işteki resmi görevlerine tercih ettikleri ve onları yerine getirmeye çalışırlarken erteleme davranışı gösterdikleri söylenebilir.

Erteleme davranışının cinsiyet, çalışılan sektör ve medeni duruma göre anlamlı farklılık gösterip göstermediğini tespit etmek amacıyla bağımsız örneklem $t$ testi analizi yapılmıştır. $\mathrm{Bu}$ analiz sonucunda katılımcıların erteleme davranışları cinsiyet, çalışılan sektöre göre farklılık göstermemektedir. Nguyen vd., tarafından yapılan çalışmada ise kadın çalışanlar erkek çalışanlara göre daha az erteleme davranışı göstermektedir (Nguyen vd., 2013). Katılımcıların medeni durumuna göre erteleme davranışları anlamlı farklılık göstermektedir. Bu sonuç Steel ve Ferrari (2013) tarafından yapılan çalışma ile benzerlik göstermektedir. Yapılan çalışmaya göre katılımcıların medeni durumları erteleme davranışı ile önemli ölçüde ilişkilidir.

İş yaşam dengesinin cinsiyet, çalışılan sektör ve medeni duruma göre anlamlı farklılık gösterip göstermediğini bulmak için yapılan bağımsız örneklem $t$ testi sonucunda iş yaşam arasındaki dengenin cinsiyet, medeni duruma göre farklılık göstermemektedir. Ancak iş yaşam arasındaki denge çalışılan sektöre göre anlamlı farklılık gösterir. Kamu çalışanlarının özel sektör çalışanlara göre iş yaşam dengelerinin daha fazla olduğu sonucu çıkarılabilir. İş ile yaşam arasında uygun bir denge kurma özellikle çalışan aileler için sorun olmaktadır. Mevcut örneklem grubunda ise evli çalışanlar ile bekar çalışanlar arasında iş yaşam dengesi farklılık göstermemektedir.

Çalışan bireylerin iş yaşamları ile özel yaşamları arasında dengeyi kurmaları üstlenilen görevlerin zamanında yerine getirilmesi ve planlamanın yapılmasını gerektirmektedir. Planlı bir hayat ertelemenin de gereksiz ertelemeden uzaklaşılarak daha stratejik nedenlerle ortaya çıkmasına neden olur. Bunun için bireylerde hem iş hayatının hem de sosyal yaşamlarının gereklerini tam anlamıyla ertelemeye başvurmadan yerine getirmeleri önemli olmaktadır. Aksi bir durumda, yani bireylerin işlerini/görevlerini zamanında yerine getirmemeleri iş yaşamında gerçekleșecek olan ertelemenin özel yaşamda da ertelemelere neden olacağı ve bunun süreklilik arz etmesi durumunda da bireylerin iş ve yaşamları arasında dengesizliğe yol açacağı düşünülmektedir.

Mevcut araştırma üzerine ulusal ve uluslararası yazında başka araştırmalara rastlanılmamıştır. Çalışanların genel erteleme davranışları üzerine yürütülen bu çalışma için diğer araştırmacılara iş yerinde erteleme ölçeğini kullanılarak iş yaşam dengesi üzerine etkinin ölçülmesi önerilmektedir. İş yerinin karakteristik özellikleri de araştırmaya dahil edilerek daha farklı sonuçların elde edileceği düşünülmektedir. 


\section{Kaynakça}

Abbasi, I. ve Alghamdi, N. G. (2015). The Prevalence, Predictors, Causes, Treatment, and Implications of Procrastination Behaviors in General, Academic, and Work Setting. International Journal of Psychological Studies, 7(1), 59-66.

Akhtar, ve Faisal Malik, M. (2016). Effect of Boredom and Flexible Work Practices on the Relationship of WFC with Procrastination and Affective Commitment: Mediation of Non-Work-Related Presenteeism. Global Journal of Flexible Systems Management, 17(4), 343-356. doi:10.1007/s40171-016-0132-6

Akın, A., Ulukök, E. ve Arar, T. (2017). İş-yaşam dengesi: Türkiye'de yapılan çalışmalara yönelik teorik bir inceleme. Afyon Kocatepe Üniversitesi İktisadi ve İdari Bilimler Fakültesi Dergisi, 19(1), 113-124.

Aksoy, H. (2017). Kamu Kurumlarında Erteleme Davranışı: Bir Kamu Kurumunda Örnek Çalışma. (Yüksek Lisans Tezi). Eskişehir Osmangazi Üniversitesi,

Altıok Gürel, P. (2018). İş-Yaşam Dengesini Sağlayan Faktörlerin Kadın Akademisyenler için Belirlenmesi: Lojistik Regresyon Analizi İstanbul Üniversitesi Kadın Araștırmaları Dergisi, 1, 31-44.

Apaydın, Ç. (2011). Öğretim Üyelerinin İşe Bağımlılık Düzeyi İle İş-Yaşam Dengesi Ve İş-Aile Yaşam Dengesi Arasındaki İlişki (Doktora Tezi). Ankara Üniversitesi, Erişim Adresi: https://tez.yok.gov.tr/UlusalTezMerkezi/tezSorguSonucYeni.jsp.

Aydemir, (2018). Çalışanlarda Erteleme Davranışı (İşyeri Prokrastinasyonu) Gelişiminde Zaman Tuzaklarının Etkisi. Anemon Muş Alparslan Üniversitesi Sosyal Bilimler Dergisi, 6(6), 10311040.

Azimi, H., Ajalli, M. ve Amari, M. (2017). Presentation of a Model for Survey of the Effective Factors on Procrastination of Employees in Organization International Journal of Management, Accounting and Economics, 4(6), 675-681. Erişim Adresi: http://www.ijmae.com/article 115032 ab469682720daa32a274144c848dc083.pdf

Aziz, , Adkins, C. T., Walker, A. G. ve Wuensch, K. L. (2010). Workaholism and Work-Life imbalance: Does Cultural Origin Influence the Relationship? International Journal of Psychology, 45(1), 72-79. doi:10.1080/00207590902913442

Beheshtifar, M., Hoseinifar, H. ve Moghadam, M. (2011). Effect Procrastination on Work-Related Stres European Journal of Economics, Finance and Administrative Sciences, 38(38), 59-64.

Bobat, , Mshololo, N. ve Reuben, (2012). A Qualitative Exploration of Women's Work-Life Balance Over the Life Course: A Case Study of Retail Manager Journal of Psychology in Africa, 22(2), 227-232. doi:10.1080/14330237.2012.10820521

Chu, A. H. ve Choi, J. N. (2005). Rethinking procrastination: positive effects of "active" procrastination behavior on attitudes and performance. $J$ Soc Psychol, 145(3), 245-264. doi:10.3200/socp.145.3.245-264

Çakıcı, Ç. D. (2003). Lise ve Üniversite Öğrencilerinde Genel Erteleme ve Akademik Erteleme Davranışının İncelenmesi. (Yüksek Lisans Tezi). Ankara Üniversitesi, Erişim Adresi: https://tez.yok.gov.tr/UlusalTezMerkezi/tezSorguSonucYeni.jsp.

Çetinkaya, A. Ş. ve Güleç, G. (2018). Sanal Takımlarda Sapkın Davranışlar. Yönetim ve Ekonomi Araştırmaları Dergisi, 16(1), 275 - 288. 
Delecta, P. (2011). Work life balance. International Journal of Current Research, 3(4), 186-189.

Dewitte, ve Lens, W. (2000). Procrastinators lack a broad action perspective. European Journal of Personality, 14, 121-140. doi:10.1002/(SICI)1099-0984(200003/04)14:2<121::AIDPER368>3.0.CO;2-\#

Dhas, D. B. (2015). A Report on the Importance of Work-Life Balance. International Journal of Applied Engineering Research, 10, 21659-21665.

Durna, U. ve Babayiğit, A. (2015). İş Görenlerin İş Yaşam Dengesine Yönelik Tutumlarının Örgütsel Bağlılık Üzerindeki Etkisi Impact on Organizational Commitment of Attitudes towards WorkLife Balance of Employee

Ferrari, J. R. (1992). Procrastination in the Workplace: Attributions for Failure among Individuals with Similar Behavioral Tendencie Personality and Individual Differences, 13(3), 315-319. doi:https://doi.org/10.1016/0191-8869(92)90108-2

Greenhaus, J. H., Collins, K. M. ve Shaw, J. D. (2003). The Relation between Work-Family Balance and Quality of Life. Journal of vocational behavior, 63(3), 510-531.

Gulbahar, Ch, A. A., Kundi, G., Qureshi, Q. A. ve Akhtar, R. (2014). Relationship between Work-Life Balance \& Organizational Commitment. Research on humanities and social sciences, 4, 1-7.

Gupta, R., Hershey, D. A. ve Gaur, J. (2012). Time perspective and procrastination in the workplace: An empirical investigation. Current Psychology, 31(2), 195-211.

Gümüș, İ. ve Türkyılmaz, B. GÜNEY AVRUPA VE TÜRKIYE’DE İŞ-YAȘAM DENGESİ: KARŞILAȘTIRMALI BİR ANALİ. Kırklareli Üniversitesi İktisadi ve İdari Bilimler Fakültesi Dergisi, 6(1), 64-88.

Hammer, C. A. ve Ferrari, J. R. (2002). Differential incidence of procrastination between blue and white-collar worker Current Psychology, 21(4), 333-338. doi:10.1007/s12144-002-1022-y

Hämmig, O. ve Bauer, G. (2009). Work-life Imbalance and Mental Health among Male and Female Employees in Switzerland. International journal of public health, 54(2), 88-95.

Harris, N. N. ve Sutton, R. I. (1983). Task Procrastination in Organizations: A Framework for Research. Human Relations, 36(11), 987-995. doi:10.1177/001872678303601102

Hen, M., Goroshit, M. ve Viengarten, (2021). How Decisional and General Procrastination Relate to Procrastination at Work: An Investigation of Office and Non-Office Worker Personality and Individual Differences, 172, 110581. doi:https://doi.org/10.1016/i.paid.2020.110581

Hooda, M. ve Devi, R. (2017). Procrastination: A Serious Problem Prevalent among Adolescents 107 113.

Igbinomwanhia, O., Iyayi, O. ve Iyayi, F. (2012). Employee Work-Life Balance as an HR Imperative. African Research Review, 6, 109-126.

Jayanthi, B. ve Vanniarajan, T. (2012). Work-Life Imbalance among Executives: A Gender Focus Global Management Review, 6(2).

Joubert, C. P. (2015). The Relationship between Procrastination and Academic Achievement of High School Learners in North West Province, South Africa.

Kanten, P. ve Kanten, (2016). The Antecedents of Procrastination Behavior: Personality Characteristics, Self-Esteem and Self-Efficacy. Pressacademia, 2, 331-331. doi:10.17261/Pressacademia.2016118653 
Klingsieck, K. B. (2013). Procrastination: When Good Things Don't Come to Those Who Wait. European Psychologist, 18(1), 24-34. doi:10.1027/1016-9040/a000138

Knaus, W. J. (2000). Procrastination, Blame, and Change. Journal of Social Behavior and Personality, $15,153-166$.

Koekemoer, E. ve Mostert, K. (2010). Work-Nonwork Interference: Preliminary Results on the Psychometric Properties of a New Instrument. SA Journal of Industrial Psychology, 36(1), 113.

Korkmaz, O. ve Erdoğan, E. (2014). İş Yaşam Dengesinin Örgütsel Bağlllık ve Çalışan Memnuniyetine Etkisi. Ege Academic Review, 14(4).

Lockwood, N. R. (2003). Work/life balance. Challenges and Solutions, SHRM Research, USA, 2-10.

Metin, U. B., Peeters, M. C. W. ve Taris, T. W. (2018). Correlates of Procrastination and Performance at Work: The Role of Having "Good Fit". Journal of Prevention \& Intervention in the Community, 46(3), 228-244. doi:10.1080/10852352.2018.1470187

Metin, U. B., Taris, T. W. ve Peeters, M. C. W. (2016). Measuring Procrastination at Work and Its Associated Workplace Aspect Personality and Individual Differences, 101, 254-263. doi:https://doi.org/10.1016/i.paid.2016.06.006

Nguyen, B., Steel, P. ve Ferrari, J. (2013). Procrastination's Impact in the Workplace and the Workplace's Impact on Procrastination. International Journal of Selection and Assessment, 21. doi:10.1111/ijsa.12048

OECD. (2011). How's life?: Measuring Well-Being. Pari

Özdevecioglu, M. ve Doruk, N. Ç. (2009). Organizasyonlarda Is-Aile ve Aile Is Çatismalarinin Çalisanlarin Is ve Yasam Tatminleri Üzerindeki Etkisi. Erciyes Üniversitesi Iktisadi ve Idari Bilimler Fakültesi Dergisi, 33, 69-99.

Pearlman-Avnion, ve Zibenberg, A. (2018). Prediction and Job-Related Outcomes of Procrastination in the Workplace. Journal of Prevention \& Intervention in the Community, 46(3), 263-278.

Pekdemir, I. ve Koçoğlu Sazkaya, M. (2014). Işkoliklik Ile Iş Yaşam Dengesi Arasindaki Ilişkide Kişilik Özelliklerinin Aracilik Rolü Üzerine Bir Araştirma. Abant İzzet Baysal Üniversitesi Sosyal Bilimler Enstitüsü Dergisi, 14(1), 309-338.

Prem, R., Scheel, T. E., Weigelt, O., Hoffmann, K. ve Korunka, C. (2018). Procrastination in Daily Working Life: A Diary Study on Within-Person Processes That Link Work Characteristics to Workplace Procrastination. Frontiers in Psychology, 9(1087). doi:10.3389/fpsyg.2018.01087

Pychyl, T. A. ve Flett, G. L. (2012). Procrastination and Self-Regulatory Failure: An Introduction to the Special Issue. Journal of Rational-Emotive \& Cognitive-Behavior Therapy, 30(4), 203-212. doi:10.1007/s10942-012-0149-5

Richert-Kaźmierska, A. ve Stankiewicz, K. (2016). Work-life balance: Does age matter? Work, 55(3), 679-688. doi:10.3233/wor-162435

Sharma, A. ve Sharma, A. (2021). Turnover Intention and Procrastination: Causal Contribution of Work-Life (Im) Balance. Journal of Contemporary Issues in Business and Government, 27(2), 1891-1901.

Sinha, D. (2013). Study of Work Life Balance @ CCIL (India), NOIDA. Journal of Management Sciences and Technology, 1(1), 8-14. 
Sirgy, M. J. ve Lee, D.-J. (2018). Work-life balance: An integrative Review. Applied Research in Quality of Life, 13(1), 229-254.

Sirois, F. ve Pychyl, T. (2013). Procrastination and the Priority of Short-Term Mood Regulation: Consequences for Future Self. Social and Personality Psychology Compass, 7(2), 115-127. doi:https://doi.org/10.1111/spc3.12011

Smith, K. (2010). Work-Life Balance Perspectives of Marketing Professionals in Generation Y. Services Marketing Quarterly, 31, 434 - 447.

Steel, P. (2010). Arousal, Avoidant and Decisional Procrastinators: Do They Exist? Personality and Individual Differences, 48(8), 926-934. doi:https://doi.org/10.1016/i.paid.2010.02.025

Steel, P. ve Ferrari, J. (2013). Sex, Education and Procrastination: An Epidemiological Study of Procrastinators' Characteristics from A Global Sample. European Journal of Personality, 27(1), 51-58. doi:10.1002/per.1851

Sturges, J. ve Guest, D. (2004). Working to live or living to work? Work/life balance early in career. Human Resource Management Journal, 14, 5-20. doi:10.1111/j.1748-8583.2004.tb00130.x

Topaloğlu, E. Ö., Sönmez, R. ve Yazgan, A. E. (2019). Çalışmaya Tutkunluk ve İş Yaşam Dengesi Arasındaki İlişki: Banka Çalışanları Üzerine. BDDK Bankacıllk ve Finansal Piyasalar Dergisi, 13(1), 66-83.

van Eerde, W. (2016). Chapter 11 - Procrastination and Well-Being at Work. In F. M. Sirois \& T. A. Pychyl (Ed), Procrastination, Health, and Well-Being (pp. 233-253). San Diego: Academic Pres

Vyas, B., Sajjan, V. ve Hanji, V. (2015). A study on work life balance among KSRTC employee International Journal of Advance Research in Computer Science and Management Studies, 3 (4), 366-373.

Weymann, E. C. (1988). Procrastination in the Workplace: Dispositional and Situational Determinants of Delay Behavior at Work. Academy of Management Proceedings, 1988(1), 226-230. doi:10.5465/ambpp.1988.4980589

Wyk, L. V. (2006). The Relationship between Procrastination and Stress in the Life of the High School Teacher. (Doctoral Dissertation). University of Proteria,

Zabelina, E., Chestyunina, Y., Trushina, I. ve Vedeneyeva, E. (2018). Time Perspective as a Predictor of Procrastination. Procedia - Social and Behavioral Sciences, 238, 87-93. doi:https://doi.org/10.1016/j.sbspro.2018.03.011

Zainab H. Bhutto, Falak Z. Mohsin ve Niazi, N. (2011). Procrastination and Impulsivenes Bahria Journal of Professional Psychology, 10, 3 - 16.

\section{Extended Abstract}

Research on procrastination has become more popular in the past 30 years (Metin et al., 2018). When the literature is examined, it is seen that most of the studies on procrastination are related to academic procrastination and conducted with sample groups of student Other studies regarding to procrastination are related to procrastination behaviors such as 'procrastination at work', 'procrastination among job seekers', and 'shopping procrastination' (Klingsieck, 2013).

There is very little research on procrastination in the workplace (van Eerde, 2016). Procrastination at work is a type of self-control failure to perform an intended job(Metin et al., 2016). Studies on procrastination behavior in individuals working in the literature are limited. These studies include task procrastination in organizations (Haris \& Sutton, 1983), the effect of procrastination in the workplace and its effect on procrastination (Nguyen et al., 2013), procrastination and welfare at work (van Eerde, 2016), procrastination in the workplace (Ferrari, 1992), procrastination among blue and white collar employees (Hammer \& Ferrari, 2002), measurement of 
procrastination at work (Metin et al., 2016), procrastination in daily working life (Prem, Scheel, Weigelt, Hoffmann, \& Korunka, 2018) is an example of delay.

Work life balance; It is the effective management of individuals' work and social lives (Akın et al., 2017). Work-life balance is a cleverly designed human resource management tool to make the employee feel good (Altıok Gürel, 2018). The integration of business life and social life is a critical task of the beginning and middle of adulthood (Jayanthi \& Vanniarajan, 2012). The balance between work and life reflects equal experiences in work and family roles (Aziz et al., 2010), and achieving a balance between work and life is important for employees and organizations as it increases productivity in the workplace and therefore affects organizational performance. At the individual level, work-life balance refers to the ability of individuals to participate in work with other aspects of their lives (home, family, health, social activity, special interests, etc.). From this point of view, work-life balance provides psychological well-being, high self-esteem, satisfaction and general harmony in an individual's life (Richert-Kaźmierska \& Stankiewicz, 2016).

Creating balance between work and life is to significantly affect the lives of individual As a result of the researches, when the studies on work-life balance in national and international literature are examined, there is no study on whether the procrastination behaviors of individuals have an effect on work-life balance. Establishing work-life balance requires a well-organized life scheme and a healthy functioning. Although it is a behavior that saves the day when individuals tend to defer in certain tasks, it is thought that when the delayed tasks come to an end, it may lead to postponement of other tasks in the individual's life and cause other behaviors that may cause imbalance in the individual's life.

In this reserach, it is aimed to find out whether workers' procrastination behaviour has an effect on their work life balance or not. In the line of this aim, literature review was built and then the research was conducted with a sample of 148 people. The study is an empirical research and questionnaire technique was employed as a data collection tool. The questionnaire consists of three parts which were elicited information on demographic variables, general procrastination scale, and work life balance scale. General procrastination scale was employed from Çakıcı (2003)'s research $(\alpha=87.2 \%)$. For Work life balance scale, the scale was used from Apaydın (2011)'s research $(\alpha=88.6 \%)$. Both scale utilised 5-points Likert scale.

There are 7 hypotheses developed in line with the research. H1: Procrastination behaviors of employees have an effect on work life balance. H2: There are significant differences between procrastination behavior and gender variable. H3: There are significant differences between procrastination behavior and the industry variable. H4: There are significant differences between procrastination behavior and marital status variable. H5: There are significant differences between work life balance and gender variable. H6: There are significant differences between the variable of work life balance and the sector worked in. H7: There are significant differences between work-life balance and marital status variable.

Regression analysis and independent sample t test analysis were performed for hypothesis test As a result of the study, it has been concluded that the general procrastination behaviors of the employees have a significant effect on their work life balance. In their study, Akhtar and Faisal Malik found that work-family conflict has a significant effect on procrastination behavior (Akhtar \& Faisal Malik, 2016). According to the results of this research, it can be said that individuals prefer their family-related duties to their official duties at work and show procrastination when trying to fulfill them. Independent sample t-test analysis was conducted to determine whether procrastination behavior differs significantly according to gender, sector of employment and marital statu As a result of this analysis, the procrastination behaviors of the participants do not differ according to gender and the sector they work in. In the study conducted by Nguyen et al. (2013) female employees show less procrastination behavior than male employee Procrastination behaviors differ significantly according to the marital status of the participant This result is similar to the work done by Steel and Ferrari (2013). According to the study, the marital status of the participants is significantly associated with procrastination. As a result of the independent sample t test conducted to find out whether the work-life balance shows a significant difference according to gender, industry and marital status, the balance between work and life does not differ according to gender and marital statu However, the balance between work and life differs significantly depending on the sector. It can be concluded that public employees have a higher work-life balance than private sector employee Establishing an appropriate balance between work and life is a problem especially for working familie In the current sample group, work-life balance does not differ between married and single employee Hence, H1, H4 and H6 hypotheses were accepted. 